Geophysical Research Abstracts

Vol. 14, EGU2012-PREVIEW, 2012

EGU General Assembly 2012

(C) Author(s) 2011

\title{
Drugs of abuse in urban groundwater. A case study: Barcelona.
}

\author{
A. Jurado (1,2), N. Mastroianni (3), E. Vazquez-Suñe (1), J. Carrera (1), I. Tubau (2), E. Pujades (1,2), C. Postigo \\ (3), M Lopez de Alda (3), D. Barceló $(3,4,5)$ \\ (1) GHS, Institute of Environmental Assessment \& Water Research (IDAEA), CSIC, Jordi Girona 18-26, 08034, Barcelona, \\ Spain. , (2) GHS, Dept Geotechnical Engineering and Geosciences, Universitat Politecnica de Catalunya, UPC-Barcelona \\ Tech, Jordi Girona 1-3, 08034, Barcelona, Spain. , (3) Department of Environmental Chemistry, Institute of Environmental \\ Assessment \& Water Research (IDAEA), CSIC, Jordi Girona 18-26, 08034 Barcelona, Spain., (4) Catalan Institute for Water \\ Research (ICRA), Emili Grahit, 101, Edifici $\mathrm{H}_{2} \mathrm{O}$, Parc Científic i Tecnològic de la Universitat de Girona, 17003 Girona, \\ Spain., (5) King Saud University, Riyadh 11451, Saudi Arabia.
}

This study is concerned with drugs of abuse (DAs) and their metabolites in urban groundwater at field scale in relation to (1) the spatial distribution of the groundwater samples, (2) the depth of the groundwater sample, (3) the presence of DAs in recharge sources, and (4) the identification of processes affecting the fate of DAs in groundwater. To this end, urban groundwater samples were collected in the city of Barcelona and a total of 21 drugs were analyzed including cocainics, amphetamine-like compounds, opioids, lysergics and cannabinoids and the prescribed drugs benzodiazepines. Overall, the highest groundwater concentrations and the largest number of detected DAs were found in zones basically recharged by a river that receives large amounts of effluents from waste water treatment plants (WWTPs). In contrast, the urbanized areas yielded not only lower concentrations but also a much smaller number of drugs, which suggests a local origin. In fact, cocaine and its metabolite were dominant in more prosperous neighbourhoods, whereas the cheaper (MDMA) was the dominant DA in poorer districts. Concentrations of DAs estimated mainly from the waste water fraction in groundwater samples were consistently higher than the measured ones, suggesting that DAs undergo removal processes in both reducing and oxidizing conditions. 